\title{
Variedades do espanhol em livro didático aprovado pelo PNLD 2012
}

\author{
Josefa Fernandes da Silva ${ }^{1}$ \\ josefafernandespanhol@gmail.com
}

\section{Resumo}

Considerando o ensino da Língua Espanhola no Brasil, o presente trabalho tem como objetivo verificar as variedades linguísticas do espanhol, presentes em livro didático aprovado pelo Plano Nacional do Livro Didático, considerando os aspectos lexicais. Foi selecionada para esta pesquisa a coleção "Enlaces - Español para jóvenes brasileños, Volume 1", contemplada pelo Plano Nacional do Livro Didático 2012, direcionada ao ensino médio. Foram abordados aspectos teóricos sobre o livro didático e o ensino brasileiro (MANTOVANI, 2009) e as variedades da língua espanhola (MORENO, 2010). As autoras da coleção são Soraia Osman, Neide Elias, Priscila Reis, Sonia Izquierdo e Jenny Valverde. Por se tratar de uma pesquisa bibliográfica, preliminarmente foi feita a leitura de alguns materiais como as resenhas dos livros de espanhol que formam parte do PNLD 2012, mais especificamente o volume 1 da coleção Enlaces. Como resultado foi verificado que há predominância da variante castelhana tanto nos livros didáticos quanto na preferência dos estudantes europeus, dada a proximidade geográfica com a Espanha. A partir dos resultados, foram levantados alguns questionamentos em relação ao ensino das variantes da língua espanhola no contexto brasileiro.

Palavra chave: Livro Didático; Variedades linguísticas; Ensino de Espanhol; PNLD 2012.

\section{Resumen}

$\mathrm{Al}$ considerar la enseñanza de la lengua española en Brasil, el presente trabajo tiene como objetivo identificar las variedades lingüísticas del español, presentes en un libro de texto aprobado por el Plan Nacional de Libro Didáctico (PNLD), centrándose en los aspectos léxicos. Fue escogida para esta investigación la Colección "Enlaces - Español para jóvenes brasileños, Volumen 1", incluida en el Plan Nacional del Libro Didáctico 2012, con destino al bachillerato. Fueron tenidos en cuenta aspectos teóricos sobre el libro de texto y la enseñanza brasileña (MANTOVANI, 2009) y las variedades del idioma español (MORENO, 2010). Los autores de la colección son Soraia Osman, Neide Elias, Priscila Reis, Sonia. Izquierdo y Jenny Valverde. Como se trata de una investigación bibliográfica, se adelantó en primer lugar, una lectura de diversos materiales como las reseñas de libros en español del PNLD 2012, más específicamente el volumen 1 de la colección Enlaces. Se descubrió que hay un predominio de la variante castellana en los libros de texto de los estudiantes europeos, dada su proximidad geográfica con España. De los resultados, se plantearon algunas preguntas relacionadas con la enseñanza de las variantes del idioma español en el contexto brasileño.

Palabra clave: libro didáctico, variedades lingüísticas, enseñanza del español, PNLD 2012.

\footnotetext{
${ }^{1}$ Especialização em Ensino de Espanhol pela Universidade Federal do Amazonas, UFAM. Graduada em LetrasLínguas e Literatura Espanhola pela Universidade Federal do Amazonas, UfAM. Professora Pela Secretaria de Educação de Qualidade e Ensino SEDUC/AM.
} 


\section{Introdução}

Falada oficialmente em mais de 20 países a língua espanhola estar presente em quatro dos cinco continentes do mundo, dentre eles a América. Como língua oficial em quase todos os países do continente americano, o idioma espanhol propagou-se com a chegada dos espanhóis a essas terras, onde, antes era habitada exclusivamente por povos nativos. Com exceção do Brasil, Guiana, Guiana Francesa e Suriname, os demais países da America do Sul falam espanhol.

Exercendo o status de língua obrigatória no Ensino Médio, o Espanhol vinha sendo implantado no Brasil por força da lei 11.161/2005. No entanto, devido à medida provisória 746/2016 o Inglês passou a ser a língua obrigatória e não mais o Espanhol. Para as escolas que oferecem a Língua Espanhola em seu currículo o Governo Federal realiza a distribuição gratuita de livros didáticos a alunos do Ensino Básico por meio do Programa Nacional do Livro Didático - PNLD. Entre os livros distribuídos se encontra o volume de Língua Estrangeira Moderna - Espanhol.

Este trabalho se propôs a analisar a variedade léxica existente em um dos volumes das coleções aprovadas no PNLD 2012, "Enlaces - Español para jóvenes brasileños, Volume 1", contemplada pelo Plano Nacional do Livro Didático 2012, direcionada ao ensino médio. De acordo com Mantovani (2009) o livro didático se apresenta como um meio de múltiplas contribuições de ensino, tanto para professores quanto para alunos; isto porque, esse material didático que é distribuído gratuitamente nas escolas, permite assim o acesso às variedades da língua espanhola em seu conteúdo.

A pesquisa baseou-se em duas considerações teóricas - o livro didático no ensino brasileiro e; as variedades linguísticas da língua espanhola. Quanto ao livro didático, consideraram-se os pressupostos de Mantovani e nas variedades linguísticas da língua espanhola, ponderaram-se os pressupostos propostos por Moreno. Na metodologia deste trabalho utilizou-se a pesquisa bibliográfica como coleta de dados. trabalho se desenvolveu conforme os tópicos seguintes: fundamentação teoria, aspectos metodológicos, apresentação e análise dos dados, encaminhamentos e as considerações teóricas que norteiam as investigações realizadas e observadas no mesmo.

\section{Fundamentação teórica}

\subsection{O livro didático e o ensino brasileiro}

Englobando um breve levantamento histórico do livro didático no Brasil, foi feita uma abordagem diacrônica, para melhor compreensão do trabalho apresentado. Com objetivo de elaborar uma enciclopédia e um dicionário da Língua Brasileira e apoiar a implantação de bibliotecas públicas em todo o país, foi criado em 1929 durante o governo de Getúlio Vargas o Instituto Nacional do Livro. O Decreto Lei $n^{\circ} 1.006$, de 30 de dezembro de 1938, instituiu o Conselho Nacional do Livro Didático, onde o livro passou a ser incluído na pauta do Governo de forma efetiva, estabelecendo-se então uma política pública federal para tratar da produção, da utilização e da implantação do livro didático.

Em 1966, a Comissão Nacional do Livro Didático (Colted) substituiu o Conselho Nacional do Livro Didático. Em 1967, depois de um acordo firmado entre o Ministério da Educação e a Agência Norte Americana para o Desenvolvimento Internacional (USAID), o MEC passou a ter recursos suficientes para a distribuição gratuita de livros por três anos. Devido as críticas à parceria entre o MEC e a Colted, em 1971 o Instituto Nacional do Livro passou a desenvolver o Programa Nacional do Livro Didático para o Ensino Fundamental (PLIDEF), assumindo as atribuições administrativas e gerenciando os recursos financeiros, anteriormente a cargo da Colted.

Em 1976, pelo Decreto $\mathrm{n}^{\mathrm{o}} 77.107$, de 04 de fevereiro de 1976, a compra dos livros distribuídos nas unidades federais foi assumida pelo Governo. O Instituto Nacional do Livro foi extinto e a Fundação Nacional do Material Escolar (Fename) ficou responsável por executar o Programa do 
Livro Didático. Em 1985, foi criada a Fundação de Assistência ao Estudante (FAE), em substituição à Fename, incorporando o Plidef. Para inovar, permitiu-se aos professores que participassem da escolha dos livros didáticos, o programa também foi ampliado com a inclusão das demais séries do Ensino Fundamental.

Somente em 1985, por meio da edição do Decreto $\mathrm{n}^{\circ}$ 91.542, de 19 de agosto de 1985, que o Plidef deu lugar ao Programa Nacional do Livro Didático (PNLD), trazendo consigo diversas mudanças. Atualmente, o PNLD está estruturado em etapas diferentes, na qual se destacam: elaboração de Edital de Convocação; inscrição das obras; triagem; préanálise; avaliação pedagógica, elaboração do Guia de Livros Didáticos; encaminhamento para as escolhas do Guia; escolha das obras pela escola; negociação, por parte do FNDE com as editoras contempladas; produção e distribuição das obras.

A elaboração do Edital de Convocação ficou a cargo do FNDE em conjunto com o Ministério da Educação, por meio da Secretaria de Educação Básica. E foi no Edital de Convocação PNLD 2012 que se encontraram as exigências para cada componente curricular. O escopo de interesse para esta pesquisa são as exigências para o componente curricular Língua Estrangeira Moderna - Espanhol. Como uma de suas especificidades, entre outros critérios, o PNLD 2012 exigiu que nas obras se contemplassem as variedades linguísticas da língua meta, conforme o Edital do PNLD 2012 (BRASIL, 2012, p 25):

[... será observado se a obra contempla variedades de tipos e gêneros de textos, de linguagem verbal e não verbal, de variações linguísticas, caracterizadoras de diferentes formas de expressão na língua estrangeira e na língua nacional.

Outro critério exigido das obras submetidas ao Edital do PNLD 2012 foi o de proporcionar a competência comunicativa, conforme exposto no Edital em questão (BRASIL, 2012, p.25.):

[...] oportuniza atividades de expressão oral em diferentes situações comunicativas, que permitam o uso de variedades, registros, léxico adequado, e estejam em interrelação com as necessidades reais da fala do jovem.

Por ser uma das exigências no edital do Plano Nacional do Livro Didático que se contemplem as variedades, a abordagem de algumas questões teóricas sobre as variedades linguísticas do espanhol foi de grande contribuição para tal desenvolvimento.

1.2 Variedades linguísticas da língua espanhola.

O ensino da língua espanhola no Brasil torna-se relevante por vários motivos, dentre tais, destacam-se: o fato de o Brasil fazer parte do MERCOSUL e a criação da lei 11.161/05 (BRASIL, 2005) que torna obrigatória a oferta da Língua Espanhola em todas as escolas do Ensino Médio no Brasil. Atualmente, por meio de uma Medida Provisória 746/2016, transformada na Lei 13.415/2017, o espanhol fica como uma segunda opção nas escolas. Apesar de não está prevista em lei nenhuma discussão quanto à variedade a ser ensinada, conhecer as variação ou variedades linguísticas contribui sobremaneira para se chegar aos objetivos. Considerando o que afirma Moreno (2010, p.15),

[...] las variedades son manifestaciones lingüísticas que responden a factores externos a la lengua. Sobre ellas inciden distintos agentes, como el momento histórico en que se manifiestan (tiempo), la región en que se usan (geografía), su entorno social (sociedad) o el contexto comunicativo en que aparecen (situación).

O ensino-aprendizagem de uma língua estrangeira não se restringe simplesmente a aquisição de conhecimentos linguísticos isoladamente, más, o tempo, a geografia, a sociedade e a situação - contexto sócio-histórico também comprometem o ensino e aprendizagem de uma língua. No continente americano, a língua espanhola se propagou, evoluindo de maneira diferente por sua extensão, sofrendo influência de vários fatores, entre eles a influência de línguas indígenas. Sobre essa questão, Moreno Fernández (2010, p.47) afirma que: 
[...] La lengua española o castellana, diseminada por un dominio geográfico de una enorme extensión y sujeta a las circunstancias que la historia le ha ido proveyendo en cada región, se manifiesta por medio de diferentes variedades dialectales o geolectales.

As variedades da língua espanhola podem ser divididas em regiões geoletais, proposta defendida por Moreno Fernándes. Segundo o autor, essas regiões abrangem as variedades linguísticas da seguinte maneira: na América: a) a variedade do Caribe, b) México e América Central; c) a variante andina; d) a variedade austral; e) a variedade do Chile; e ainda f) a variedade presente nos Estados Unidos. Na Espanha encontram-se: g) a variedade castelhana; h) a variedade canária, e i) a variedade andaluza. As variedades geoletais podem ser identificadas nos planos fônico, morfossintático e lexical (MORENO FERNÁNDEZ, 2010). No que concerne a este trabalho, o foco recai sobre o plano lexical. Assim, a seguir, são abordadas algumas considerações sobre o as variedades geoletais da língua espanhola no plano lexical.

Conforme estudos feitos, no espanhol da América, há uma predominância de palavras com influências indígenas, origem africana, além de usos americanos generalizados. Exemplos que podem ser mencionados no plano lexical do espanhol da América com influências indígenas ou africanas são os apresentados na tabela a seguir.

\begin{tabular}{|c|c|c|c|c|}
\hline $\begin{array}{l}\text { Variedade do } \\
\text { Caribe }\end{array}$ & $\begin{array}{c}\text { México e América } \\
\text { Central }\end{array}$ & Andina & Austral & Chile \\
\hline $\begin{array}{l}\text { Guanajo } \\
\text { 'pavo', chango } \\
\text { 'especie de } \\
\text { mono' }\end{array}$ & $\begin{array}{l}\text { Alberca 'piscina', } \\
\text { chapulín 'langosta' }\end{array}$ & $\begin{array}{l}\text { Andinis- mo } \\
\text { 'escalada', } \\
\text { hostigoso } \\
\text { 'molestoso' }\end{array}$ & $\begin{array}{l}\text { Bombacha } \\
\text { 'braga', Cana } \\
\text { 'policía' }\end{array}$ & $\begin{array}{l}\text { Pisco } \\
\text { 'aguardente', } \\
\text { Colocolo } \\
\text { 'Gato Montés' }\end{array}$ \\
\hline
\end{tabular}

A seguir serão descritos alguns exemplos característicos do espanhol da Espanha.

\begin{tabular}{|c|l|l|}
\hline Espanhol castelhano & \multicolumn{1}{|c|}{ Espanhol andaluz } & Espanhol de Canárias \\
\hline $\begin{array}{l}\text { Caguica 'miedoso', } \\
\begin{array}{l}\text { Garrulo 'persona poco } \\
\text { elegante' }\end{array}\end{array}$ & $\begin{array}{l}\text { Cangallo 'persona alta } \\
\text { y flaca', gachas 'mimo, } \\
\text { caricia' }\end{array}$ & $\begin{array}{l}\text { Andoriña, 'golondrina', } \\
\text { Cachetes 'mejillas' }\end{array}$ \\
\hline
\end{tabular}

Quanto a África, existem duas regiões que propiciam ao espanhol características bem específicas, configurando: a) O espanhol de Magreb; e

b) O espanhol Guiné Equatorial.

São exemplos típicos do espanhol de Magreb e Guiné Equatorial: 


\begin{tabular}{|c|c|}
\hline Espanhol de Magreb & Espanhol de Guiné Equaltorial \\
\hline $\begin{array}{l}\text { Plaza 'mercado, Mujada } \\
\text { 'almohada' }\end{array}$ & Lloro 'deseo', Cayuco 'canoa' \\
\hline
\end{tabular}

\section{Aspectos Metodológicos}

Por se tratar de uma pesquisa bibliográfica, a priori foi feita a leitura de materiais como as resenhas dos livros de espanhol que formam parte do PNLD 2012, foi analisado o volume 1 da coleção Enlaces- español para jóvenes brasileño, aprovada no Plano Nacional do Livro Didático 2012, destinada ao Ensino Médio. Foi feita a leitura das fundamentações teóricas e em seguida se iniciou a elaboração desta pesquisa. Para uma melhor visualização e compreensão, consta no quadro informações relevante sobre a edição:

\begin{tabular}{|l|l|l|l|}
\hline \multicolumn{1}{|c|}{ Coleção } & \multicolumn{1}{|c|}{ Autores } & $\begin{array}{c}\text { Volume escolhido } \\
\text { como objeto de } \\
\text { estudo }\end{array}$ & Editora \\
\hline $\begin{array}{l}\text { Enlaces: Español } \\
\text { para jóvenes } \\
\text { brasileños }\end{array}$ & $\begin{array}{l}\text { Soraia Osman, Neide } \\
\text { Elias, Priscila Reis, } \\
\text { Sonia Izquierdo e Jenny } \\
\text { Valverde }\end{array}$ & Volume I & Macmillan \\
\hline
\end{tabular}

No livro selecionado verificou-se a presença das variedades linguísticas, mas especificamente no plano léxico. A coleção é composta por três volumes com oito unidades cada um e uma revisão para consolidar os temas gramaticais aprendidos a cada duas unidades. A unidade compõe-se didaticamente da seguinte maneira: Página de entrada; Hablemos de; iy no solo esto!; Manos a la obra; ¡En otras palabras!; Como te decía; Más cosas; Así me veo.

Se inclui ao final do livro um apêndice que contem as seguintes partes:

- Un poco más de todo

- Vestibular

- Te digo e me dices

- Glosario español-portugués

- Tabla de verbos

\section{Apresentação e análise dos dados}

$\mathrm{Na}$ apresentação do volume, os autores ressaltam a importância da Língua Estrangeira, não somente como ferramenta para a vida profissional, mas também como veículo para se conhecer culturas diferentes. Ao destacar o contexto brasileiro, Osman et al (2010) afirma:

El idioma español ocupa un lugar cada vez más relevante incluso en países donde no es idioma oficial pero las comunidades inmigrantes hispanas o de origen hispano tienen cada vez más peso. En el caso de Brasil, esta situación cobra relevancia por la cercanía de los países hispanoamericano cuyas relaciones comerciales, políticas y culturales experimentan un crecimiento constante. (Osman et al, 2010, p. 3) 
Comprovam-se a necessidade que há de se oferecerem obras didáticas que atendam ao interesse desse público. Sobre as atividades que envolvem a obra, os autores afirmam ainda que serão abordadas atividades contrastivas entre as variantes hispânicas (Osman et al, 2010), fator relevante para o objetivo deste trabalho.

A coleção está composta por três volumes, que estão divididos em oito unidades, e cada unidade está dividida em oito seções. Nas páginas 4 e 5 verifica-se a especificidade de cada seção, apresentando o volume I da coleção Enlaces - español para jóvenes brasileños. Na seção Hablemos de..., por exemplo, Osman et al (2010) declara:

A partir de modelos de diálogos de la vida cotidiana, presentaciones, entrevistas, etc, se introduce el tema transversal y el contenido gramatical, comunicativo o lexical que se va a desarrollar en la unidad. Son actividades para completar, relacionar, leer, contestar, expresar opinión, etc. (Osman et al, 2010, p. 4)

Visando cumprir os objetivos propostos neste trabalho, verificou-se apenas o plano lexical presente neste material didático, de modo que, no volume analisado, na seção intitulada "Manos a la obra", percebeu-se que se propõem atividades em que se apresentam as variações do espanhol, segundo Osman et al (2010):

El objetivo principal de esta sección es desarrollar la competencia gramatical de manera sistematizada entre uso y forma. Se presenta una serie de ejercicios de tipología variada para consolidar, fijar y practicar los contenidos. Cuenta con un apartado de estudio contrastivo entre el español y el portugués, además de un trabajo orientado hacia la fonética y ortografía, contrastando las diferentes semejanzas con el portugués y/o las variantes del español. (Osman et al 2010, p. 4)

Tomando como orientação as duas seções citadas anteriormente, foram analisados os vocabulários e as variedades presentes no volume em estudo. Pertencente à seção "Hablemos de..." (unidade 1, p. 14), encontramos um exercício específico de léxico sobre profissões em que os alunos são levados apenas a fazer uma relação entre vocabulário e imagens. Não se observou até então nenhum exercício que desperte o ensino da variante no plano lexical.

Na seção "Hablemos de..." (unidade 3, p. 48), comprovou-se a presença de mais um exercício que envolve aprendizagem de léxico, mas não se trata também de uma atividade que faça um contraste da variedade léxica. Seguindo ainda com as analises pelas unidades, mais uma vez na seção "Hablemos de..." (unidade 4, p. 64), encontraram-se vocabulários relacionados com partes de uma casa, assim como objetos pertencentes a cada cômodo. Nos enunciados somente se exige a identificação entre imagens e vocabulários.

Analisando a proposta da seção "Manos a la obra", observou-se exercícios contrastivos entre o espanhol e o português, mas não se verificou a presença de atividades sobre as variedades no plano lexical.

Ainda que não se tenha verificado atividades no plano lexical, tivemos a preocupação em verificar a que variedade(s) pertenciam os vocabulários que se apresentam no livro. Como resultado encontramos vocabulários de usos mais frequentes na Espanha, assim como vocabulários presentes tanto nas variantes da Espanha como da América. Também encontramos vocabulários usados mais frequentemente na América

Prosseguindo ainda com a observação ao que exige o Edital PNLD 2012 (BRASIL,2012) podemos verificar que:

Para Língua Estrangeira Moderna (Inglês e Espanhol), será observado se a obra: (1) reúne um conjunto de textos representativos das comunidades falantes da língua estrangeira, com temas adequados ao ensino médio, que não se veiculem estereótipos nem preconceitos em relação às culturas estrangeiras envolvidas, nem á nossa própria em relação a elas;

Conforme observado no Edital, há uma preocupação que se promova o conhecimento das diversas comunidades falantes da língua estrangeira. 
Ao considerar o crescimento do ensino do Espanhol como Segunda Língua ou como Língua Estrangeira no continente europeu, Moreno (2010) destaca o valor do tratamento das variedades do espanhol, o que reafirma sua importância no processo de ensino-aprendizagem de Língua Estrangeira. Para fomentar esta questão, Moreno (2010) acrescenta:

[ ] La cuestión sobre la variedade del español que há de predominar en la enseñanza de esta lengua en Europa puede fragmentarse en tres preguntas menores cuyas respuestas ayudan a construir el panorama general. ¿De donde son los materiales didácticos que se manejan para la enseñanza del español en Europa? Pues, son mayoritariamente de España o asesorados y supervisionados por autores y especialistas de España. Así pues, los métodos y recursos didácticos están muy ligados a la variedade castellana del español. Por otro lado, ¿cuáles son las expectativas y necesidades de los estudiantes europeus en relación con el español? Pues, en un grado destacado tienen que ver con intereses y posibilidades ligados a España, por la cercanía física, poe el atractictivo de su cultura y geografía, por su condición de puerta europea hacia el continente americano. (MORENO,2010, p.17)

Ficou evidente a predominância da variante castelhana tanto nos livros didáticos quanto na preferência dos estudantes europeus por essa variante, dada a proximidade geográfica com a Espanha. No entanto, cabem alguns questionamentos: por que a preferência dos europeus tende à variante castelhana? Será que as demais variantes da língua espanhola presentes na Espanha, a saber, a andaluza e a canaria, são (des)consideradas? De que forma(s) e medida(s) as variantes hispano-americanas da língua espanhola são (des) consideradas?

Ao considerar a realidade brasileira, propuseram-se outros questionamentos: as variantes da língua espanhola são consideradas e contempladas nos livros didáticos utilizados no Brasil para o ensino de E/LE? A exemplo do que ocorre na Europa, também existe a predominância de alguma(s) variantes(s) da língua espanhola nas obras didáticas para o ensino de E/LE no Brasil?
Dada a proximidade com países hispano-falantes americanos, as variantes da língua espanhola presentes na América possuem maior peso nas obras didáticas para o ensino de E/LE no Brasil? De acordo com o Edital do PNLD 2012, não há preferência(s) por qualquer uma das variantes da língua espanhola. Ao contrário, espera-se que as coleções aprovadas para o ensino de E/LE contemplem as diferentes variantes, tanto as presentes na Espanha como as na América.

\section{Conclusão}

A preocupação com o tema desta pesquisa surgiu a partir de estudos feitos durante a realização da especialização Lato Sensu em Ensino de Espanhol: língua e literaturas. De acordo com a linha de pesquisa escolhida, pareceu relevante estudar uma das obras destinada ao ensino de espanhol no ensino regular no Brasil, comtemplada pelo Programa Nacional do Livro Didático/2012 para o Ensino Médio, uma vez que, quando se ensina uma língua estrangeira, esta se dá por meio de um modelo linguístico.

O espaço territorial onde se fala o espanhol é imenso. Isso se deve a questões históricas e, por isso, houve uma propensão para a predominância das variedades linguísticas que se expandiram junto com a história. Assim, é de se esperar que essas variedades de expansão estejam contempladas em obras didáticas que tenham a finalidade de se ensinar a língua estrangeira. Visando o estudo do espanhol no Brasil, buscou-se analisar uma das coleções comtempladas pelo PNLD. Mediante a pesquisa, chegou-se à conclusão de que as variantes linguísticas são colocadas na obra em estudo. No entanto, houve alguns questionamentos que ficaram sem respostas, mas que certamente poderão ser respondidos em estudos posteriores.

\section{REFERÊNCIAS:}

Brasil. Linguagens, códigos e suas tecnologias/ Secretaria de Educação Básica. Brasília: Ministério da Educação, Secretaria da Educação Básica, 2000. 239p. 
Mantovani, Kátia Paulilo. O programa Nacional do livro Didático Impactos na Qualidade do Ensino Público. 2009. Dissertação - Faculdade de Filosofia, Letras e Ciências Humanas, Universidades de são Paulo, 2009.

Moreno, Francisco Fernández. Qué español enseñar?. Madrid: Arco/Libros, 2000.
.Las variedades de la lengua española y su enseñanza. Madrid: Arco/Libros, 2010.

Osman, Soraia. Enlaces: español para jóvenes brasileños. São Paulo: Macmillas, 2010. Disponível em: http://portal.mec.gov.br/pnld/ apresentacao. Acesso: 14/04/2017. 